DOI: 10.12731/wsd-2018-4-178-188

УДК 616-008.6:616-008.9:616-092

\title{
ОЦЕНКА КОЛИЧЕСТВА ЦИРКУЛИРУЮЩИХ ЭНДОТЕЛИОЦИТОВ ПЕРЕФЕРИЧЕСКОЙ КРОВИ ПРИ МЕТАБОЛИЧЕСКОМ СИНДРОМЕ У НАСЕЛЕНИЯ ХАКАСИЯ
}

Берсенёва О.А., Агеева Е.С.

Цель. Оценить вклад эндотелиальной дисфункции у пациентов с метаболическим синдромом.

Материалы и методы. Обследовано 183 пациента в возрасте от 25 до 65 лет, которые были рандоминизированы на 2 группь. В первую группу вошли 60 практически здоровых лии, во вторую группу - 123 пачиента с метаболическим синдромом.

Метаболический синдром диагностировали по критериям ВНОК (2009). Критериями исключения из исследования являлись: тяжелые соматические, онкологические, гематологические, психические заболевания.

Статистическая обработка результатов исследования проводилась с использованием пакета статистических программ «StatPlus».

Результаты. Выявлена эндотелиальная дисфункиия, различия биохимических показателей, характеризуюших компоненты метаболического синдрома (нарушения углеводного и липидного обмена), особенности антропометрических показателей у хакасов и европеоидов. Новым является оценка количества иңикклируюших эндотелиочитов периферической крови.

Заключение. Таким образом, эндотелиальная дисфункция является важным механизмом в патогенезе, формирующим межкомпонентные взаимосвязи и особенности метаболического синдрома у хакасов и европеоидов

Ключевые слова: метаболический синдром; эндотелиальная дисфункция; инсулинорезистентность; дислипидемия; артериальная гипертензия; гипергликемия. 


\title{
THE ANALYSIS OF CIRCULATING ENDOTHELIOCYTES IN PERIPHERAL BLOOD AT PATIENTS WITH METABOLIC SYNDROME FROM KHAKASSIA
}

\author{
Bersenyeva O.A., Ageeva E.S.
}

Background: The role of endothelial dysfunction in patients with metabolic syndrome was investigated.

Materials and methods: The study involved 183 patients aged 25 to 65 who which consist of 2 groups. The first group included 60 healthy subjects, in the second group - 123 patients with metabolic syndrome.

Diagnosis of metabolic syndrome performed by recommendation ASSC (2008). The exclusion criteria from study was heavy somatic, oncological, hematological and mental diseases. Statistical analysis was performed using the application package StatPlus.

Results: the endothelial dysfunction, differences of biochemical analysis was observed in all groups of patient with metabolic syndrome. So differences were established in carbohydrate and lipid metabolism. The features anthropometric indicators were identified at study of Khakas's and Europeoid's patients. New data was the amount circulation of endothelial cells in peripheral blood.

Conclusion: thus, endothelial dysfunction is important mechanism of pathogenesis. It is forming inter component relationship and features of metabolic syndrome genesis from Khakas 's and Europeoid's patients

Keywords: metabolic syndrome; endothelial dysfunction; insulin resistance; dyslipidemia; arterial hypertension; hyperglycemia.

Метаболический синдром - собирательное понятие, объединяющее группу патологических состояний, проявляющихся метаболическими, гормональными и клиническими проявлениями, в основе которых инсулинорезистентность $[1$, с. 32-37; 2, с. 1-10]. При этом наиболее часто инсулинорезистентность встречается в виде ассоциированной патологии с алиментарным ожирением, заболеваниями сердечнососудистой системы (СС3), артериальной гипертензией (АГ), атеросклерозом, патогенетически связанных с эндотелиальной дисфункцией [3, с. 14-22; 4, с. 5-12].

Учитывая механизмы, приводящие к развитию инсулинорезистентности, мы предположили, что метаболический синдром сопровождается системной необратимой реакцией внутреннего клеточного пласта крове- 
носных сосудов различного калибра, которая приводит к его десквамации, с последующей циркуляцией в кровотоке.

Существует мнение, что содержание десквамированных эндотелиальных клеток в периферической крови отражает степень повреждения сосудов, что было подтверждено более высоким значением данного показателя у больных сахарным диабетом, ишемической болезнью сердца, с цереброваскулярными заболеваниями [5, с. 50-52; 6, с. 578-587; 7, с. 1100-1105]. Число эндотелиоцитов прямо коррелирует с показателем эндотелиальной дисфункции - фактором Виллебранда, указывая на диагностическую ценность определения десквамированных эндотелиальных клеток в крови [8, с. 9-11].

В связи с этим большой интерес представляет изучение эндотелиальной дисфункции у населения Республики Хакасия с метаболическим синдромом.

\section{Цель исследования}

Оценить вклад эндотелиальной дисфункции в патогенез метаболических нарушений у населения Республики Хакасия.

\section{Материалы и методы}

Для решения поставленных задач на базе ГБУЗ РХ РКБ им. Г.Я. Ремишевской обследовано 183 пациента с МС возрасте от 25 до 65 лет. Средний возраст пациентов составил 50 (42-54) лет. Возраст обследованных в контрольной группе - 43 (36-47) лет. Для изучения явления этнического полиморфизма всех обследуемых разделили на 2 группы пришлого и коренного населения Республики Хакасия. К коренному населению относили хакасов, а к пришлому - европеоидов, проживающих на территории Республики Хакасия. В качестве контрольной группы использовали результаты исследования 60 условно здоровых добровольцев. Метаболический синдром диагностировали по критериям ВНОК (2009). Критериями исключения из исследования являлись: наличие тяжелых соматических, онкологических, гематологических, эндогенных психических заболеваний; отсутствие согласия принимать участие в исследовании.

Всем больным проведено комплексное клинико-лабораторное исследование: определялись антропометрические показатели, биохимический анализ крови, который включал определение уровней общего холестерина (XC), липопротеинов высокой плотности (ЛПВП), липопротеинов низкой плотности (ЛПНП), триглицеридов (ТГ), уровня гликемии натощак, с-пептида, индекса инсулинорезистентности, уровня СРБ.

Количественная оценка циркулирующих эндотелиоцитов в периферической крови производилась по методу J. Hladovec [9, с. 1033-1036]. 
Эндотелиоциты подсчитывались в камере Горяева (рис. 1). От одного пациента обсчитывалось 10 проб по 10 мкл обогащенной клетками плазмы. Суммируя данные каждой из 10 проб, получали количество циркулирующих эндотелиальных клеток в 100 мкл обогащенной клетками плазмы. Количество циркулирующих эндотелиальных клеток выражалось в $10^{5}$ кл./л. У здоровых доноров количество циркулирующих эндотелиоцитов равно $1-3 \times 10^{5}$ кл./л, при 1 степени эндотелиальной дисфункции - 4-6×105 кл./л, при 2 степени $-7-12 \times 10^{5}$ кл./л, при 3 степени - 13-18 $\times 10^{5}$ кл./л, при 4 степени $19-25 \times 10^{5}$ кл./л, при критической эндотелиальной дисфункции с высоким риском сердечно-сосудистых осложнений - более $25 \times 10^{5}$ кл./л [10, с. 5].

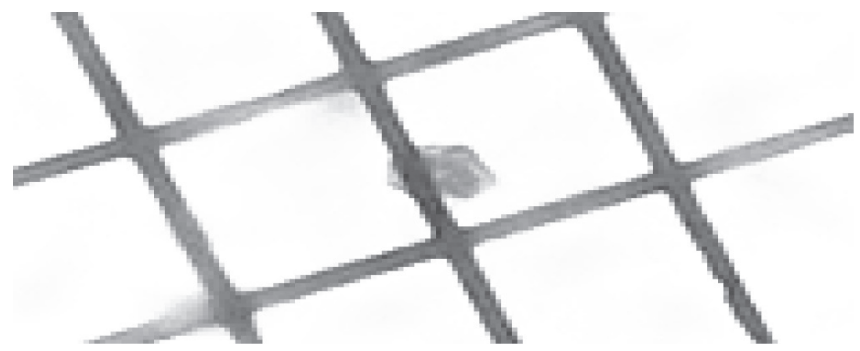

Рис. 1. Микрофотография десквамированной эндотелиальная клетки в переферической крови камере Горяева. Окраска метиленовым синим ( $1 \%$ водный раствор), ув $\times 400$.

Статистическая обработка результатов исследования проводилась с использованием пакета статистических программ «StatPlus». Для проверки гипотезы о нормальности распределения использовался критерий Колмогорова-Смирнова. Учитывая, что все данные имели распределения, отличные от нормального, вычисления средних значений представлены в виде медианы (Ме) и интерквартильного размаха (25 и 75 перцентилей). При анализе различий значений был использован критерий Манна-Уитни. Различия считались статистически значимыми при $\mathrm{p}<0,05$. Для проверки наличия взаимосвязей между полученными данными в исследуемых группах использовался коэффициент ранговой корреляции Спирмена, при р <0,05.

\section{Результаты и обсуждение}

Ведущим клиническим признаком метаболического синдрома у хакасов и европеоидов является абдоминальное ожирение. Однако выраженность ожирения в исследуемых группах имеет отличия. Европеоиды с метаболическим синдромом имеют более высокие показатели индекса мас- 


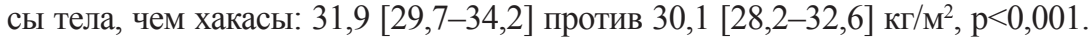
У европеоидов с метаболическим синдромом, по сравнению с хакасами, увеличивается масса жировой ткани 23,66 [20,0-28,7] против 26,2 [21,6-31,0] кг, $\mathbf{p}<0,001$, объем общей жировой ткани 25,6 [21,7-31,1] против 28,4 [23,4$33,6]$ л, $\mathrm{p}<0,001$, объем подкожной жировой ткани $17,15[13,5-21,8]$ против $20,76[15,626,7]$ л, $\mathrm{p}<0,001$, в то время как у хакасов преобладает объем висцеральной жировой ткани $8,9[7,5-9,6]$ против 7,5 [4,5-9,6] л, $\mathrm{p} \geq 0,05$.

Увеличение массы жировой ткани при ожирении сопровождается ее инфильтрацией макрофагами, повышением вторичной продукции хемоаттрактанта моноцитов-1 (МСР-1) и провоспалительных цитокинов, инфильтрацией преадипоцитами и эндотелиальными клетками. При этом нарушается регуляция баланса между сосудистыми факторами, особенно между эндогенной продукцией оксида азота (NO) и системой эндотелинов, что в свою очередь сопровождается изменениями инсулинстимулированной эндотелий зависимой вазодилятации [11, с. 36-40; 12, с. 44-48].

Показатели липидного и углеводного обмена у пациентов с МС были статистически значимо выше, чем в группе контроля, как среди пришлого населения, так и среди коренного населения. Европеоиды с метаболическим синдромом имеют более высокие показатели глюкозы, чем хакасы: 6,12 [4,81-9,2] против 9,3 [6,65-12,7] ммоль/л, p<0,05. При гипергликемии в эндотелиальных клетках активируется фермент протеинкиназа-С и процессы перекисного окисления липидов, увеличивая проницаемость сосудистых клеток для белков, угнетается сосудорасширяющая функция эндотелия и нарушается эндотелий зависимая релаксация сосудов [13, с. 1319-1331; 14, с. 1113]. Аналогичная тенденция наблюдалась в отношении гликозилированного гемоглобина. Европеоиды с метаболическим синдромом имели более высокие показатели гликозилированного гемоглобина, в сравнении с хакасами: $5,4[4,7-9,4]$ против $8,3[6,6-9,6] \%, \mathrm{p}<0,05$. Наряду с этим хакасы с метаболическим синдромом имели более высокие показатели С-пептида по сравнению с европеоидами: 2,2 [1,4-3,1] против 0,23 $[0,19-0,34]$ нг/мл, $\mathrm{p}<0,001$. Возможно, этот факт является отражением особенностей патогенеза метаболического синдрома который реализуется в виде популяционного диморфизма среди жителей Республики Хакасия.

У европеоидов с метаболическим синдромом уровень триглицеридов был выше, чем в группе контроля 2,25 [1,7-3,07] против 1,32 [0,9-1,5] ммоль/л, $\mathrm{p}<0,05$. Аналогичная тенденция наблюдалась и в группе хакасов с метаболическим синдромом 1,82 [0,87-2,40] против 1,07 [0,6-1,41] ммоль/л, $\mathrm{p}<0,05$. Уровень липопротеидов низкой плотности у хакасов с MC был выше, чем в группе контроля 3,13 [2,59-3,8] против 2,78 [2,39- 
$3,05]$ ммоль/л, $\mathbf{p}<0,001$. Уровень липопротеидов высокой плотности у хакасов с метаболическим синдромом был ниже, чем в группе контроля 1,2 $[0,97-1,4]$ против $1,3[1,12-1,4]$ ммоль/л, $\mathrm{p} \geq 0,05$. Индекс атерогенности у хакасов с метаболическим синдромом был выше, чем в группе контроля $3,34[2,62-4,78]$ против 2,98 [2,61-3,36] p<0,05. Статистически значимых межпопуляционных различий в отношении параметров липидного обмена не обнаружено. Дислипидемия повышает экспрессию адгезивных молекул на поверхности эндотелиальных клеток, повышает проницаемость эндотелия, снижает эндотелий зависимую релаксацию сосудов, способствую прогрессированию атерогенеза [15, с. 82-88].

Известно, что возрастание содержания СРБ в плазме сопровождается нарушением функции эндотелия посредством способности белка острой фазы воспаления активировать продукцию эндотелиоцитами эндотелина-1 и ИЛ-6 [16, с. 71-73; 17, с. 24-35]. В нашем исследовании концентрация СРБ у европеоидов с МС составила 19,5 [6,5-25,5] мг/дл, что было выше аналогичного показателя у здоровых доноров - 1,9 [1,1-3,3] мг/дл, различия носили статистически значимый характер $(\mathrm{p}<0,001)$. Аналогичная тенденция наблюдалась и у хакасов с метаболическим синдромом: концентрация СРБ у хакасов с МС составила 4,5 [1,1-10] мг/дл, что было статистически значимо выше аналогичного показателя у здоровых доноров - 1,5 [1-4,9] мг/дл, $\mathbf{p}<0,001$. При выявлении межпопуляционных различий, было показано, что у европеоидов при МС содержание СРБ было статистически значимо выше, чем в группе хакасов, статистических различий у хакасов и европеоидов в группе здоровых доноров не было. Полученные нами данные свидетельствуют о повышении в группе больных МC маркера воспалительной реакции как системного, так и локального воспаления, который может определять степень эндотелиальной дисфункции, изменяя состояние эластических свойств сосудистой стенки.

Количество десквамированных эндотелиоцитов периферической крови у европеоидов с метаболическим синдромом составило 7,0 [7,0-12,0] $\times 10^{5}$ кл./л, что было статистически значимо выше в сравнении с группой здоровых доноров 4,0 [4,0-5,0] × $10^{5}$ кл./л, $(\mathrm{p}<0,001)$. Аналогичная тенденция наблюдалась и у хакасов с метаболическим синдромом. Количество десквамированных эндотелиоцитов периферической крови у хакасов с МС составило $8,0[5,0-13,0] \times 10^{5}$ кл./л, что было статистически значимо выше в сравнении с группой здоровых 4,0 [3-5] ×105 кл./л, $(\mathrm{p}<0,001)$. При выявлении межпопуляционных различий показано что статистически значимых различий по количеству десквамированных эндотелиоцитов периферической крови между хакасами и европеоидами 
как среди лиц с метаболическим синдромом, так и в группе здоровых доноров выявлено не было ( $>0,05)$. Усиленное отслоение эндотелиоцитов от базальной мембраны во всех исследуемых группах больных с метаболическим синдромом может являться свидетельством их значительного повреждения и свидетельствовать о выраженности эндотелиальной дисфункции. В ходе исследования эндотелиальной дисфункции у пациентов с МС коренного и пришлого населения РХ можно сказать о формировании при данной патологии множественных порочных кругов, среди которых эндотелиальная дисфункция играла центральную роль в реализации патогенеза метаболического синдрома и ассоциированных с ним клинических состояний. Аналогичные закономерности были показаны и в работах многих исследователей [18, с. 134-142; 19, с. 38-53; 20, с. 125-128].

\section{Заключение}

Таким образом, выявленная нами эндотелиальная дисфункция является интегративным процессом и отражает взаимосвязь компонентов метаболического синдрома, как у коренного, так и у пришлого населения Республики Хакасии. Однако механизмы развития эндотелиальной дисфункции отличались у хакасов и европеоидов.

\section{Список литературы}

1. Азимова М.Н., Бахшалиев А.Б., Кахраманова С.М. Влияние моксонидина и комбинации моксонидина с ивабрадином на параметры инсулинорезистентности у пациентов с метаболическим синдромом // Казанский мед. журнал. 2015. №1. С. 32-37.

2. Roberts C.K., Hevener A.L., Barnard R.J. Metabolic Syndrome and Insulin Resistance: Underlying Causes and Modification by Exercise Training // Comprehensive Physiology, 2013, vol. 3, №1, pp.1-58. doi:10.1002/cphy.c110062.

3. Булаева Н. И., Голухова Е. З. Эндотелиальная дисфункция и оксидативный стресс: роль в развитии кардиоваскулярной патологии // Креативная кардиология. 2013. №1. С. 14-22.

4. Muniyappa R., Sowers J.R. Role of Insulin Resistance in Endothelial Dysfunction // Reviews in endocrine \& metabolic disorders, 2013, vol. 14, №1, pp. 5-12. doi:10.1007/s11154-012-9229-1.

5. Петрищев Н.Н., Беркович О.А., Власов Т.Д. и др. Диагностическая ценность определения десквамированных эндотелиальных клеток в крови // Клиническая лабораторная диагностика. 2001. № 1. С. 50-52.

6. Schmidt D.E., Manca M., Hoefer I.E. Circulating endothelial cells in coronary artery disease and acute coronary syndrome // Trends in Cardiovascular Medicine, 2015, vol. 25. № 7. P. 578. 
7. Lampka M. et al. Circulating endothelial cells in coronary artery disease // Kardiologia polska, 2010, vol. 68. № 10, pp. 1100-1105.

8. Цвингер С.М., Говорин А.В., Алексенко Е.Ю. Маркеры эндотелиальной дисфункции при остеоартрозе // Дальневосточный медицинский журнал. 2009. №3. C. 9-11.

9. Hladovec J. et al. Circulating endothelial cells in acute myocardial infarction and angina pectoris // Klinische Wochenschrift. 1978. vol. 56. № 20, pp. 1033-1036.

10. Инжутова А.И. Способ оценки эффективности сосудистой терапии по выраженности эндотелиальной дисфункции / Свидетельство о государственной регистрации, рег. №2455641 от 10.07.2012. М.: Роспатент, 2012.

11. Постникова Е.В., Смирнов И.Е., Маслова О.И. и др. Клинико-патогенетическое значение эндотелиальной дисфункции в формировании ожирения У детей // Российский педиатрический журнал. 2013. №5. С. 36-40.

12. Ливзан М.А., Колбина М.В., Матошина И.В. и др. Гормоны жировой ткани и неалкогольная жировая болезнь печени при метаболическом синдроме // Дневник казанской медицинской школы. 2014. №. 4. С. 44-48.

13. Geraldes P., King G.L. Activation of protein kinase $\mathrm{C}$ isoforms and its impact on diabetic complications // Circ. Res. 2010; vol. 106, pp. 1319-1331.

14. Смирнова Е.Н., Лоран Е.А., Шулькина С.Г. и др. Исследование функции эндотелия с помощью холодовой пробы у пациентов с метаболическим синдромом // Современные проблемы науки и образования. 2014. № 6. С. 1113.

15. Линдина М.Л., Шишкин А.Н., Воловникова В.А. Особенности внутрипочечной гемодинамики у пациентов с метаболическим синдромом // Нефрология. 2015. Т. 19. № 4. С. 82-88.

16. Милютина О.В., Чичерина Е.Н. Прогностическая роль С-реактивного белка в развитии риска кардиальных событий // Российский Кардиологический Журнал. 2011. Т. 87, №.1. С. 71-73.

17. Сушкина И.Ф. Оценка функционального состояния эндотелия, факторов иммунного ответа и качества жизни у больных с острым коронарным синдромом и нарушением углеводного обмена: дис. ... канд. мед наук: 14.01.04. Ростов на Дону, 2015. 184 с.

18. Бекезин В.В. Инсулинорезистентность и эндотелиальная дисфункция, их вклад в развитие метаболического синдрома у детей и подростков // Владикавказский медико-биологический вестник. 2012. Т. 15, №. 23. С. 134-142.

19. Polovina M.M., Potpara T.S. Endothelial dysfunction in metabolic and vascular disorders // Postgrad. Med. 2014. Vol. 126, №2, pp. 38-53.

20. Коваленко Л.В., Белова Е.А. Васкулоэндотелиальный фактор роста и десквамированные эндотелиальные клетки у пациентов с ожирением // Вестник НовГУ. 2014. №78. С. 125-128. 


\section{References}

1. Azimova M.N., Bakhshaliev A.B., Kakhramanova S.M. Vliyanie moksonidina i kombinatsii moksonidina s ivabradinom na parametry insulinorezistentnosti u patsientov s metabolicheskim sindromom [Effects of Moxonidine and Combination of Moxonidine and Ivabradine on Insulin Resistance in Patients with Metabolic Syndrome]. Kazanskiy meditsinskiy zhurnal [Kazan Medical Journal]. 2015. № 1, pp. 32-37.

2. Roberts C.K., Hevener A.L., Barnard R.J. Metabolic Syndrome and Insulin Resistance: Underlying Causes and Modification by Exercise Training. Comprehensive Physiology, 2013, vol. 3, №1, pp.1-58. doi:10.1002/cphy.c110062.

3. Bulajeva NI, Golukhova EZ. Endotelial'naya disfunktsiya i oksidativnyy stress: rol' v razvitii kardiovaskulyarnoy patologii [Endothelial dysfunction and oxidative stress: a role in development of cardiovascular pathology]. Kreativnaya kardiologiya [Creative cardiology]. 2013. № 1, pp. 14-22.

4. Muniyappa R., Sowers J.R. Role of Insulin Resistance in Endothelial Dysfunction. Reviews in endocrine \& metabolic disorders, 2013, vol. 14, №1, pp. 5-12. doi:10.1007/s11154-012-9229-1.

5. Petrishchev N.N., Berkovich O.A., Vlasov T.D. et al. Diagnosticheskaya tsennost' opredeleniya deskvamirovannykh endotelial'nykh kletok v krovi [Diagnostic value of detection of desquamated endothelial cells in blood]. Klinicheskaya laboratornaya diagnostika [Clinical laboratory diagnostics]. 2001. № 1, pp. 50-52.

6. Schmidt D.E., Manca M., Hoefer I.E. Circulating endothelial cells in coronary artery disease and acute coronary syndrome. Trends in Cardiovascular Medicine, 2015, vol. 25. № 7, pp. 578.

7. Lampka M., et al. Circulating endothelial cells in coronary artery disease. Kardiologia polska, 2010, vol. 68. № 10, pp. 1100-1105.

8. Tsvinger S.M., Govorin A.V., Aleksenko E.Yu. et al. Markery endotelial'noy disfunktsii pri osteoartroze [The markers of endothelial dysfunction in patients with osteoarthritis]. Dal'nevostochnyy meditsinskiy zhurnal [Far eastern medical journal]. 2009. № 3, pp. 9-11.

9. Hladovec J. et al. Circulating endothelial cells in acute myocardial infarction and angina pectoris. Klinische Wochenschrift. 1978. vol. 56. № 20, pp. 1033-1036.

10. Inzhutova A.I. Sposob otsenki effektivnosti sosudistoy terapii po vyrazhennosti endotelial'noy disfunktsii [The method for evaluating the effectiveness of vascular therapy in expressing endothelial dysfunction]. M.: Rospatent, 2012.

11. Postnikova E.V., Smirnov I.E., Maslova O.I.et al. Kliniko-patogeneticheskoe znachenie endotelial'noy disfunktsii $\mathrm{v}$ formirovanii ozhireniya u detey [Clinical and pathogenetic significance of endothelial dysfunction in the formation 
of obesity in children]. Rossiyskiy pediatricheskiy zhurnal [Russian Pediatric Journal]. 2013. № 5, pp. 36-40.

12. Livzan M.A., Kolbina M.V., Matoshina I.V.et al. Gormony zhirovoy tkani i nealkogol'naya zhirovaya bolezn' pecheni pri metabolicheskom sindrome [Hormones adipose tissue and non-alcoholic fatty liver disease at metabolic syndrome]. Dnevnik kazanskoy meditsinskoy shkoly [Diary of the Kazan medical school]. 2014. № 4, pp. 44-48.

13. Geraldes P., King G.L. Activation of protein kinase C isoforms and its impact on diabetic complications. Circ. Res. 2010; vol. 106, pp. 1319-1331.

14. Smirnova E.N., Loran E.A., Shul'kina S.G. et al. Issledovanie funktsii endoteliya s pomoshch'yu kholodovoy proby u patsientov s metabolicheskim sindromom [The study of endothelial function via cold test in patients with metabolic syndrome]. Sovremennye problemy nauki i obrazovaniya [Modern problems of science and education]. 2014. № 6, pp. 11-13.

15. Lindina M.L., Shishkin A.N., Volovnikova V.A. Osobennosti vnutripochechnoy gemodinamiki u patsientov s metabolicheskim sindromom [Features of renal hemodynamics in patients with metabolic syndrome]. Nefrologiya [Nephrology]. 2015. vol 19, № 4, pp. 82-88.

16. Milyutina O.V., Chicherina E.N. Prognosticheskaya rol' S-reaktivnogo belka v razvitii riska kardial'nykh sobytiy. [Prognostic role of C-reactive protein in the development of risk of cardiac events]. Rossiyskiy Kardiologicheskiy Zhurnal [Russian Journal of Cardiology]. 2011. vol 87, № 1, pp. 71-73.

17. Sushkina I.F. Otsenka funktsional'nogo sostoyaniya endoteliya, faktorov immunnogo otveta i kachestva zhizni u bol'nykh s ostrym koronarnym sindromom i narusheniem uglevodnogo obmena [Evaluation of the functional state of the endothelium, immune response factors and quality of life in patients with acute coronary syndrome and violation of carbohydrate metabolism]. Rostov na Donu, 2015. $184 \mathrm{pp}$.

18. Bekezin V.V. Insulinorezistentnost' i endotelial'naya disfunktsiya, ikh vklad v razvitie metabolicheskogo sindroma u detey i podrostkov [Insulin resistance and endothelial dysfunction.Contribution to the development of metabolic syndrome in children and adolescents]. Vladikavkazskii mediko-biologicheskii vestnik [Vladikavkaz medical-biological bulletin.]. 2012. Vol. 15, №23, pp. 134-142.

19. Polovina M.M., Potpara T.S. Endothelial dysfunction in metabolic and vascular disorders. Postgrad. Med. 2014. Vol. 126, №2, pp. 38-53.

20. Kovalenko L.V., Belova E.A. Vaskuloendotelial'nyy faktor rosta i deskvamirovannye endotelial'nye kletki u patsientov s ozhireniem [The vascular endothelial growth factor and the desquamated endothelial cells in patients with obesity]. Vestnik NovGU [Bulletin of NovSU]. 2014. № 78, pp. 125-128. 


\section{ДАННЫЕ ОБ АВТОРАХ}

Берсенёва Ольга Александровна, преподаватель кафедры фундаментальной медицины и гигиены

Федеральное государственное бюджетное образовательное учреждение выстего образования «Хакасский государственный университет им. Н.Ф. Катанова».

ул. Ленина, 90, Республика Хакасия, г. Абакан, 655000, Российская Федерация

mylanya2010@yandex.ru

Агеева Елизавета Сергеевна, доцент, доктор медицинских наук, профессор кафедры фундаментальной медицины и гигиены Федеральное государственное бюджетное образовательное учреждение выстего образования «Хакасский государственный университет им. Н.Ф. Катанова».

ул. Ленина, 90, Республика Хакасия, г. Абакан, 655000, Российская Федераиия

ageevaeliz@rambler.ru

\section{DATA ABOUT THE AUTHORS}

Berseneva Olga Alexandrovna, Teacher of the Department of Fundamental Medicine and Hygiene

Katanov Khakass State University

90, Lenin Str., Republic of Khakassia, Abakan, 655000, Russian Federation

mylanya2010@yandex.ru

SPIN-code: 7310-0675

ORCID: 0000-0001-5622-2364

ResearcherID: C-6356-2018

Ageeva Elizaveta Sergeevna, Associate Professor, Doctor of Medical Sciences, Professor of the Department of Fundamental Medicine and Hygiene Katanov Khakass State University

90, Lenin Str., Republic of Khakassia, Abakan, 655000, Russian Federation

ageevaeliz@rambler.ru

SPIN-code: 9958-7298

ORCID: 0000-0003-3770-2965

ResearcherID: Q-4704-2016 